\title{
Diode Laser Turbinate Reduction in the Treatment of Symptomatic Inferior Turbinate Hypertrophy
}

\author{
Pradipta Kumar Parida • Gopalakrishnan Surianarayanan • \\ Arun Alexander • Sunil Kumar Saxena • \\ Krishnapriya Santhosh
}

Received: 21 November 2011/ Accepted: 9 February 2012/Published online: 19 February 2012

(C) Association of Otolaryngologists of India 2012

\begin{abstract}
To evaluate the efficacy of diode laser turbinate reduction procedure in treatment of symptomatic inferior turbinate hypertrophy (ITH) and to study the effect of it on mucociliary clearance of nose. This prospective study was carried out over 45 patients with symptomatic ITH refractory to medical management from July 2009 to March 2010 in Department of E.N.T, Jawaharlal Institute of Post Graduate Medical Education and Research, Pondicherry, India. Each symptom (nasal obstruction, rhinorrhoea, sneezing, headache, hyposmia and snoring) was assessed by visual analogue scale (VAS). Mucociliary clearance was measured by saccharin transit time (STT). All patients underwent diode laser turbinate reduction (LTR) under local anesthesia. The patients were followed up at 1 week, 1, 3 and 6 months postoperatively. During each follow up visit, symptoms were reassessed by VAS score. Difference between preoperative and postoperative VAS score was statistically significant. All patients had significant symptomatic improvement which started from 1 week postoperatively and persisted throughout the follow up period. Prolongation of STT following diode laser turbinate reduction was significant. SST returned back to preoperative value by the end of 6 months. Crusting and pain were the main postoperative complaints. Diode laser turbinate reduction is safe, minimally invasive and effective in relieving the symptoms associated with ITH and can be performed on a day care basis under local anaesthesia. Longer follow up is required to assess the development of late complications and recurrence of symptoms after LTR.
\end{abstract}

P. K. Parida $(\square)$ · G. Surianarayanan · A. Alexander .

S. K. Saxena - K. Santhosh

Department of E.N.T, Jawaharlal Institute of Post Graduate

Medical Education and Research, Pondicherry 605006, India

e-mail: drpradipta04@gmail.com
Keywords Turbinate hypertrophy · Diode laser · Mucociliary clearance

\section{Introduction}

Nasal obstruction secondary to Inferior turbinate hypertrophy (ITH) may be a minor nuisance to some people but to others it is a source of considerable discomfort and affects the quality of life to a great extent. ITH usually observed in allergic rhinitis, vasomotor rhinitis, and chronic hypertrophic rhinitis. Therefore, a patient with ITH may also have sneezing, rhinorrhea and headache in addition to nasal obstruction.

Chronic inflammation of the nasal mucosa seen in allergic or vasomotor rhinitis leads to deposition of collagen in the submucosal tissue of the turbinates and remodelling of the turbinate bone. This leads to the development of ITH. Initially the symptoms may be responsive to medical management. Topical decongestants, antihistamines and steroids form the mainstay of treatment for ITH. Surgical reduction of inferior turbinate to relieve the symptoms is usually done for the cases refractory to medical treatment $[1,2]$. There are a wide variety of techniques available for the surgical reduction of inferior turbinate like total or partial turbinectomy, turbinoplasty, chemical cautery, diathermy, radiofrequency volumetric tissue reduction (RFVTR), laser turbinate reduction (LTR) and cryotherapy[1, 2]. Most of these techniques provide satisfactory results for a variable period and they are associated with various adverse effects like post operative bleeding, crusting, pain and synechiae formation. Optimal surgical technique for inferior turbinate reduction should strike a balance among effective turbinate volume reduction, preservation of nasal function and avoidance of complications. 
LTR is an effective and simple method for treatment of ITH. The advantages of laser surgery are lack of bleeding, high precision and good healing of the wound. Different types of lasers are used in the medical field like $\mathrm{CO}_{2}$ laser,

Nd: YAG laser, argon laser, diode laser and KTP laser. This study uses diode laser for turbinate reduction procedures. Its tissue-cutting effect is comparable to that of the $\mathrm{CO} 2$ laser, its coagulation effect is comparable to that of the argon laser, and it results in a slightly higher degree of absorption by tissue than does the Nd: YAG laser. LTR can be performed under local anaesthesia and are short duration surgeries. It has minimal intraoperative and postoperative complications and is usually well tolerated by the patients. This prospective study was done to find out the efficacy of diode laser in the treatment of ITH and to study the effect of the procedure on the mucociliary clearance mechanism of the nose.

\section{Materials and Methods}

This prospective study was carried out over the 45 patients with symptomatic bilateral ITH who are refractory to medical treatment in department of Otorhinolaryngology, Jawaharlal Institute of Post Graduate Medical Education and Research, Pondicherry from July 2009 to March 2010. The study was reviewed and approved by the Ethical committee of our institution. Patients with previous history of nasal surgeries or trauma, gross deviation of nasal septum or nasal polyposis, and malignancy of nose and paranasal sinuses, were excluded from the study.

History of nasal obstruction, rhinorrhea, headache, sneezing, and hyposmia not responding to medical treatment along with other symptoms of allergic and non allergic rhinitis were noted and the symptom assessment was done with the visual analogue scale (VAS) in which the patient rates his symptoms from a score of 0 to 10 , score 0 being asymptomatic and 10 being the most severe symptoms. Mucociliary clearance was measured by saccharin transit time (STT). All patients underwent a detailed general and otorhinolaryngological examination including diagnostic nasal endoscopy. All patients underwent routine investigations including computerized tomography of the paranasal sinuses to rule out sinus pathology. All the patients underwent Diode LTR under local anaesthesia and procedure was done under endoscopic guidance.

The Diode laser (Portable $980 \mathrm{~nm}$ wavelength Fox diode laser from A.R.C) was used in contact mode with fibre diameter of $600 \mu \mathrm{m}$, power of $5 \mathrm{~W}$ in continuous wave mode for 100-140 s. Multiple applications were made along the inferior turbinate as required.

No patient required postoperative packing. Patients were given paracetamol for pain relief, if required. Patients were called for called for follow up after 1 week, 1, 3 and 6 months of surgery. During each postoperative visit, the symptoms were reassessed using VAS and postoperative morbidity like pain, bleeding and crusting were noted. Mucociliary clearance was assessed in each visit with the help of STT. Nasal endoscopy was done during each visit and findings were noted.

All the data were analysed using SPSS 18 (Statistical Package for the Social sciences: SPSS version 18.0, for Windows, Chicago, IL) statistical software. Mann-Whitney test was employed to analyse the difference between preoperative and postoperative VAS score. For all the tests, $p$ value of less than 0.05 was taken as significant.

\section{Observation and Analysis}

Out of 45 patients, 29 were females and 16 were males. All the patients were in the age group of 18-50 years. Preoperative symptoms and their average VAS scores are shown in Table 1. All patients in the study had bilateral ITH without any other intranasal and sinus pathology on nasal endoscopy and CT scan. The mean preoperative STT was $18.34 \mathrm{~min}$ (SD 4.38). The means duration of surgery was $10.8 \min$ (SD 5.05).

None of the patients had any major complications. Repeated crustings was main complaint. Crusting over the inferior turbinate was present in 88.9 and $66.6 \%$ at 1 and 3 months of follow up (Table 2). All of patients had shrunk intact inferior turbinate at 3 months of follow up. Postoperative follow up VAS score of individual symptom and mean STT are shown in Tables 3 and 4 respectively. The number of patients who had relief in individual symptom 6 months after surgery is shown in Table 5. The relief in symptom was either complete or partial.

\section{Discussion}

Nasal obstruction caused by ITH causes significant morbidity as it affects the daily activities of the patients. The first line of treatment for ITH is medical and surgery is

Table 1 Preoperative symptoms and average VAS score

\begin{tabular}{lll}
\hline Symptoms & $\begin{array}{l}\text { No of patients having } \\
\text { the symptoms (\%) }\end{array}$ & $\begin{array}{l}\text { Average } \\
\text { VAS }\end{array}$ \\
\hline Nasal obstruction & $45(100)$ & 9.26 \\
Nasal secretions & $45(100)$ & 7.28 \\
Sneezing & $45(100)$ & 7.13 \\
Headache & $35(75.5)$ & 4.65 \\
Hyposmia & $23(51.06)$ & 3.58 \\
Snoring & $24(53.3)$ & 4.28 \\
\hline
\end{tabular}


Table 2 Postoperative complications

\begin{tabular}{llllll}
\hline Complications & $\begin{array}{l}\text { Immediate post- } \\
\text { operative } \\
\text { number }(\%)\end{array}$ & $\begin{array}{l}\text { 1 week post- } \\
\text { operative } \\
\text { number (\%) }\end{array}$ & $\begin{array}{l}\text { 1 month post- } \\
\text { operative } \\
\text { number (\%) }\end{array}$ & $\begin{array}{l}3 \text { months post- } \\
\text { operative } \\
\text { number (\%) }\end{array}$ & $\begin{array}{l}6 \text { months post- } \\
\text { operative } \\
\text { number }(\%)\end{array}$ \\
\hline Bloody nasal discharge & $4(8.9)$ & $12(26.64)$ & Nil & Nil & Nil \\
Pain & $13(28.9)$ & $10(22.2)$ & Nil & Nil & Nil \\
Crusting & $45(100)$ & $42(92.3)$ & $40(88.9)$ & Nil & Nil \\
Mucosal edema & $4(8.9)$ & Nil & Nil & Nil & Nil \\
Synechiae & Nil & Nil & & & \\
\hline
\end{tabular}

Table 3 Comparison of preoperative and postoperative VAS score of individual symptom $p$ value $<0.05$ considered as statistically significant

\begin{tabular}{|c|c|c|c|}
\hline Symptoms & $\begin{array}{l}\text { Postoperative } \\
\text { Follow up periods }\end{array}$ & $\begin{array}{l}\text { Postoperative } \\
\text { VAS score }\end{array}$ & $\begin{array}{l}\text { Difference between } \\
\text { preoperative and post- } \\
\text { operative VAS score ( } p \text { value) }\end{array}$ \\
\hline \multirow[t]{5}{*}{ Nasal obstruction } & Preoperative & 9.26 & \\
\hline & 1 week & 8.21 & $<0.0001$ \\
\hline & 1 month & 3.84 & $<0.0001$ \\
\hline & 3 months & 2.19 & $<0.0001$ \\
\hline & 6 months & 2.82 & $<0.0001$ \\
\hline \multirow[t]{5}{*}{ Rhinorrhoea } & Preoperative & 7.28 & \\
\hline & 1 week & 3.72 & $<0.0001$ \\
\hline & 1 month & 2.86 & $<0.0001$ \\
\hline & 3 months & 2.27 & $<0.0001$ \\
\hline & 6 months & 2.68 & $<0.0001$ \\
\hline \multirow[t]{5}{*}{ Sneezing } & Preoperative & 7.13 & \\
\hline & 1 week & 3.27 & $<0.0001$ \\
\hline & 1 month & 2.79 & $<0.0001$ \\
\hline & 3 months & 2.38 & $<0.0001$ \\
\hline & 6 months & 2.76 & $<0.0001$ \\
\hline \multirow[t]{5}{*}{ Headache } & Preoperative & 4.65 & \\
\hline & 1 week & 2.47 & $<0.0001$ \\
\hline & 1 month & 2.24 & $<0.0001$ \\
\hline & 3 months & 2.21 & $<0.0001$ \\
\hline & 6 months & 2.22 & $<0.0001$ \\
\hline \multirow[t]{5}{*}{ Hyposmia } & Preoperative & 3.58 & \\
\hline & 1 week & 2.96 & 0.0039 \\
\hline & 1 month & 2.44 & 0.0005 \\
\hline & 3 months & 2.41 & 0.0005 \\
\hline & 6 months & 2.34 & 0.0005 \\
\hline \multirow[t]{5}{*}{ Snoring } & Preoperative & 4.28 & \\
\hline & 1 week & 3.59 & 0.0010 \\
\hline & 1 month & 2.43 & $<0.0001$ \\
\hline & 3 months & 1.56 & $<0.0001$ \\
\hline & 6 months & 1.87 & $<0.0001$ \\
\hline
\end{tabular}

usually reserved for cases refractory to medical treatment. Various procedures are currently performed to reduce the volume of the inferior turbinate. The variety of surgical methods used indicates a lack of consensus regarding the optimal surgical technique. The goal of the surgery should be an optimal volume reduction to diminish complaints, preservation of the physiologic function and less side effects. The focus of the study was more on the qualitative 
Table 4 Mean Saccharin transit time (STT)

\begin{tabular}{lll}
\hline Follow up & STT in min & $\begin{array}{l}\text { Difference between } \\
\text { preoperative and post- } \\
\text { operative STT( } p \text { value })\end{array}$ \\
\hline Preoperative & 18.34 & \\
1 week postoperatively & 27.2 & $<0.0001$ \\
1 month postoperatively & 23.98 & $<0.0001$ \\
3 months postoperatively & 20.32 & $<0.0001$ \\
6 months postoperatively & 18.46 & 0.2776 \\
\hline
\end{tabular}

$p$ value $<0.05$ considered as statistically significant

Table 5 Calculation of symptomatic relief 6 months postoperatively

\begin{tabular}{lll}
\hline Symptoms & $\begin{array}{l}\text { No of patients having } \\
\text { symptoms } \\
\text { preoperatively }\end{array}$ & $\begin{array}{l}\text { No of patients who } \\
\text { got relief 6 months } \\
\text { post operatively }\end{array}$ \\
\hline Nasal obstruction & 45 & $39(86.7 \%)$ \\
Nasal discharge & 45 & $39(86.7 \%)$ \\
Sneezing & 45 & $39(86.7 \%)$ \\
Headache & 34 & $27(79.4 \%)$ \\
Hyposmia & 23 & $11(47.8 \%)$ \\
Snoring & 24 & $22(91.7 \%)$ \\
\hline
\end{tabular}

improvement of symptoms on VAS score rather than the improvement in objective scores. The symptom assessment was done with the VAS in which the patient rates his symptoms from a score of $0-10$; score 0 being asymptomatic and 10 being the most severe symptoms. Maxwell [3] has described VAS as easy to use, sensitive and accurate when testing differences within subject comparisons. Lund [4] has also described the use of linear visual scales in the office evaluation of nasal symptoms. He noted that they were of great value for comparing sequential evaluations.

Ciprandi et al. [5] reported that a significant, very strong correlation has been observed between VAS scores for allergic symptoms and nasal airflow resistance via rhinomanometry. They concluded that VAS for assessing allergic symptoms, especially in nasal obstruction, may be considered a reliable predictor in the absence of objective rhinologic examinations. Their study provides evidence to support the use of the VAS as an outcome variable in clinical practice or research. All patients had statistically significant improvement in all symptoms VAS scores at 1 week, 1, 3 and 6 months postoperatively.

There was significant improvement in nasal obstruction in all cases. In the initial 2-3 days following the surgery, nasal obstruction worsened in most of the patients. This may have been due to the postoperative edema and crusting. But by the end of the first week all patients showed statistically significant improvement in nasal obstruction. Min et al. [6] reported that in diode LTR group had significant improvement in nasal obstruction and significant decrease in nasal airway resistance 6 months following the surgery. Janda et al. [1] showed that diode LTR group did not have much improvement in the symptom of nasal obstruction during the first 2-4 weeks owing to the postoperative edema and crusting but they had statistically significant improvement of the nasal airflow and nasal cavity volume 6 months and 1 year after laser surgery respectively. A subjective improvement of nasal airflow was described by 86 and $76 \%$ of patients after 6 months and 1 year of laser treatment respectively in their study [1]. Volk et al. [7] reported that diode laser turbinoplasty led to a mean improvement of nasal airflow of $37.1 \%$ eight weeks after the surgery. A total of $73.2 \%$ of patients reported improvement of nasal obstruction and only $12.2 \%$ experienced deterioration. Rhee et al. [8] compared RFVTR and diode LTR found that eight weeks after in LTR group, $87.5 \%$ of the patients showed improvement in both the severity and frequency of nasal obstruction and statistically significant improvement was observed at 4 weeks after treatment. In our study all the patients had significant improvement in nasal obstruction 1 week after surgery and relief of nasal obstruction persisted in $86.7 \%$ of patients 6 month postoperatively.

Preoperatively all patients had the complaints of rhinorrhea. There was statistically significant improvement in rhinorrhea after 1 week. In the first week, 2 patients complained of worsening of rhinorrhea; but this was not found to be statistically significant. The relief in rhinorrhea may be attributed to destruction of highly vascular submucosa, seromucinous glands and incision of branches of posterior nasal nerve, which plays a crucial role in sneezing and hypersecretion. But At the end of the 6 month follow up, relief in rhinorrhea persisted in $86.7 \%$ of the patients. A study by Supiyaphun et al. [9] showed that KTP LTR produces significant reduction in rhinorrhea post operatively.

Preoperatively all of the patients had significant sneezing. At the end of the 6 month follow up period it was found that $86.7 \%$ of the patients had got significant relief in sneezing. The reason for relief of sneezing may be attributed to destruction of the branches of posterior nasal nerve. These findings are similar to other studies $[10,11]$.

At the end of the 6 month follow up period $79.4 \%$ of the patients showed an improvement in headache. This may be because of improved nasal patency.

Hyposmia was present in $23(51.06 \%)$ patients in our study. The relief in hyposmia was seen in $11(47.8 \%)$ of the patients 6 months postoperatively. The improvement may be attributed to the improvement in nasal patency following surgery. This finding is similar to other reported series 
$[8,11]$. Rhee et al. [8] compared the effect of radiofrequency and laser reduction of inferior turbinate on olfactory improvement. They found that after 8 post-operative weeks, half of the sample showed significant improvement in olfaction in both the groups. Maskell et al. [11] reported that laser turbinate reduction produced a significant improvement in the sense of smell post operatively. Min et al. [6] found that there were no significant post-operative changes in olfactory acuity using the butanol threshold test in patients undergoing diode LTR. Relief of snoring was achieved in $91.7 \%(22 / 24)$ of the patients 6 months postoperatively. This may due to relief of nasal obstruction.

STT was significantly prolonged at 1 week, 1 month and 3 month post-operatively. STT returned preoperative value by 6 months. This implies laser impairs the mucociliary clearance mechanism of the nose significantly in the initial months. This finding is similar to Sapci et al. [12]. A study by Janda et al. [1] and Min et al. [6] found that there was no significant variation in comparison to the preoperative measurements 1 year after laser treatment. This is in accordance with the present study which showed that the saccharin transit times normalized by 6 months post-operatively. Rhee et al. [8] found that there were no changes in the saccharine transit time they placed the saccharine particle on the septum instead of on the inferior turbinate

There were no significant intraoperative complications. In the immediate post operative period all patients had nasal crusting. Only $17.8 \%$ of the patients had edema. Thirteen $(28.9 \%)$ of the patients had immediate post operative period was pain. Only $6.7 \%$ of the patients had bleeding. The bleeding was managed conservatively. Ten $(22.2 \%)$ of the patients complained of trivial pain at the end of 1 week. No patient had pain at the end of 1,3 and 6 months post operatively. In Papon et al. [2], [3] series, only $2.1 \%$ of the patients had pain that underwent $\mathrm{Nd}$ : YAG laser turbinate reduction.

Twelve $(33.3 \%)$ of the patients had bleeding at end of 1 week. In all the cases the bleeding was controlled with topical decongestant drops. At the end of 1, 3 and 6 months follow up; no patient had any similar complaint. The reported incidence of postoperative bloody discharge following LTR is $0-20.1 \%$ [8, [13]. Crusting was the main complaint following diode LTR. At the end of 1 week $92.6 \%$, at the end of 1 month $88.9 \%$ and at the end of 3 months in $66.6 \%$ of the patients had complaints of crusting. Maskell et al. [10] found that $29.5 \%$ of the patients who underwent laser turbinectomy had visible crusting at the 2 week follow up. Almost all the nasal crusting had settled by 3 months. In a study by Papon et al. [13], crusting occurred in $41.6 \%$ of the patients who underwent Nd: YAG laser turbinate reduction. There was no incidence of synechiae formation, septal perforation, epiphora or osteonecrosis of the turbinate bone in our study.

\section{Conclusions}

This prospective study dealt with one of the commonest conditions encountered by otolaryngology practitioners all over the world; that of inferior turbinate hypertrophy unresponsive to medical management. Diode LTR procedures are safe, minimally invasive, effective in relieving the symptoms associated with ITH, and can be performed on a day care basis under local anaesthesia. There are no serious intraoperative and postoperative complications. The improvement in postoperative average VAS score of symptom was statistically significant. LTR impairs the mucociliary clearance mechanism to a greater degree but the mucociliary clearance returns back to normal within 6 months. Crusting and pain were main complaint following LTR. Longer follow up is required to assess the development of late complications and recurrence of symptoms after LTR.

Funding None

Conflict of interest None.

\section{References}

1. Janda P, Sroka R, Betz CS, Grevers G, Leunig A (2002) Ho:YAG and diode laser treatment of hyperplastic inferior nasal turbinates. Laryngorhinootologie 81:484-490

2. Cavaliere M, Mottola G, Iemma M (2005) Comparison of the effectiveness and safety of radiofrequency turbinoplasty and traditional surgical technique in treatment of inferior turbinate hypertrophy. Otolaryngol Head Neck Surg 133:972-978

3. Maxwell C (1978) Sensitivity and accuracy of the visual analogue scale: a psycho-physical classroom experiment. Br J Clin Pharmacol 6:15-24

4. Lund V (1992) Office evaluation of nasal obstruction. Otolaryngol Clin North Am 25:803-816

5. Ciprandi G, Mora F, Cassano M, Gallina AM, Mora R (2009) Visual analog scale (VAS) and nasal obstruction in persistent allergic rhinitis. Otolaryngol Head Neck Surg 141:527-529

6. Min YG, Kim HS, Yun YS, Kim CS, Jang YJ, Jung TG (1996) Contact laser turbinate surgery for the treatment of idiopathic rhinitis. Clin Otolaryngol Allied Sci 21:533-536

7. Volk GF, Pantel M, Guntinas-Lichius O, Wittekindt C (2010) Prognostic value of anterior rhinomanometry in diode laser turbinoplasty. Arch Otolaryngol Head Neck Surg 136:10151019

8. Rhee CS, Kim DY, Won TB, Lee HJ, Park SW, Kwon TY, Lee CH, Min YG (2001) Changes of nasal function after temperaturecontrolled radiofrequency tissue volume reduction for the turbinate. Laryngoscope 111:153-158

9. Supiyaphun P, Aramwatanapong P, Kerekhanjanarong V, Sastarasadhit V (2003) KTP laser inferior turbinoplasty: an alternative procedure to treat the nasal obstruction. Auris Nasus Larynx 30:59-64

10. Abdullah Nazik E, Al-Muslet Nafie A (2010) Use of the Nd-YAG Laser for Inferior Turbinectomy: A Comparative Study. Clin Med Insights 3:11-15 
11. Maskell S, Eze N, Patel P, Hosni A (2007) Laser inferior turbinectomy under local anaesthetic: a well tolerated out-patient procedure. J Laryngol Otol 121:957-961

12. Sapçi T, Sahin B, Karavus A, Akbulut UG (2003) Comparison of the effects of radiofrequency tissue ablation, $\mathrm{CO}_{2}$ laser ablation, and partial turbinectomy applications on nasal mucociliary functions. Laryngoscope 113:514-519
13. Papon JF, Choutet M, Rugina M, Peynègre R, Coste A, BrugelRibère L. Refractory chronic rhinitis: long-term outcomes after LASER Nd: YAG treatment. Presented in 2003 at the EAACI, Paris, and in 2003 at the 110th French ORL and head and neck surgery meeting 